normally considered low temperatures, Umklappprocesses are frequent in metallic sodium, and that at room temperatures such processes account for some 90 per cent of the resistivity.

Prof. G. O. Jones (Queen Mary College) summarized the work which has been carried out on super-conductivity at pressures of 10,000 atmospheres and above. Although the electron-phonon interaction theory of superconductivity, developed by Fröhlich and Bardeen, had appeared to account more or less exactly for the change in transition temperatures with change in isotopic mass, the effect of varying the volume is by no means straightforward. For metals which would be regarded as normal with respect to their ordinary electrical properties under high pressure, having a resistivity which varies approximately as $V^{2 \gamma}$, where $\gamma$ is the Grüneisen constant, the superconducting behaviour varies enormously. In some cases the transition temperature varies according to expectation as $V^{\gamma}$, but in others the variation is more nearly proportional to $V^{4} \gamma$, and in one case (thallium) there is a reversal in the sense of the variation at about 1,000 atmospheres.
In a short contribution, Dr. P. G. Klemens (Sydney) spoke of the conduction properties of monovalent metals at very low temperatures and explained a discrepancy which appears to exist between thermal and electrical conductivity. Dr. A. B. Pippard (Cambridge) in a final contribution dealt with acoustic absorption in metal crystals. He described how an analysis, by standard methods of conduction theory, of the attenuation of a longitudinal ultrasonic wave shows that, so long as the electronic free path is shorter than the wave-length, the attenuation varies as the square of the frequency, but, when the free path is long compared with the wave-length, the attenuation is proportional to the frequency and independent of free path. The transition region has been investigated by Bömmel and found to show qualitative agreement with theory. The result for a long free path is identical with that derived by the arguments used to describe electron-phonon interaction in quantum theory of conduction. It seems likely, then, that the result derived 'classically' by consideration of electron trajectories is valid over the whole range of free paths.

H. JONES

\title{
OBITUARIES
}

\section{Dr. J. H. Partridge}

John Henry Partridge, a senior member of the Research Laboratories of the General Electric Company, Ltd., died on November 30, 1956, at the age of fifty-three. For many years Partridge had been head of the department of the Laboratories concerned with glass, refractories and ceramics. He was a man who loved to do things with his own hands and he was always anxious to translate, as rapidly as possible, laboratory findings into works' application. He was very frequently to be found in the works both of his own Company and of other firms in the glass industry, giving his help generously. He had suffered from a heart attack some six years ago, and the restraint which his medical adviser attempted to impose upon him he found very hard to bear. It was very difficult to stop him trying to carry out a full programme of works' visits and society meetings, when in the interest of his health he should at times have been taking life more quietly. His ill-health never interfered with his great sense of fun, and he was a delightful colleague with whom to travel either to a works of the Company or to some international congress.

Partridge was a most conscientious man, and this virtue was reflected in his record of service to scientific and technical societies. He was a member of the Council of the Society of Glass Technology for several periods since 1934, and was honorary secretary of the Society during 1946-49. At the time of his death he was in office as president, having been elected in April 1956; election to this office was an honour which Partridge deeply appreciated, and he had undertaken the duties with characteristic energy. $\mathrm{He}$ was a member of the Ceramic Society and a Founder Fellow of the Institute of Ceramics; he had travelled much on the Continent to attend international congresses on glass.

In the G.E.C. Laboratories he had done a great deal of work on the development of new glasses and refractories; he was the author of two monographs, one on "Refractory Materials for the Glass Industry" and the other on "Glass-to-Metal Seals". He had written many papers on these and related subjects.

Dr. Partridge was educated at King Edward VI Grammar School, Birmingham, and in 1921 he entered the School of Metallurgy in the University of Birmingham, and in due course he obtained the degree of Ph.D. During the period 1925-26 he was awarded a grant from the Department of Scientific and Industrial Research, and a Carnegie Scholarship from the Iron and Steel Institute. In 1947 he received his D.Sc. for his contribution to scientific and technological knowledge in the fields of glass and refractories.

His colleagues in the General Electric Company and a much wider circle of colleagues in the glass industry in Britain and abroad will feel keenly the loss of a man whose enthusiasm and good humour had endeared him to them-a man whose enjoyment of life was so infectious. His friends will have great sympathy for his wife and three children.

\section{R. W. Douglas}

\section{Prof. Joseph Varga}

Prof. Joseph VArga, a member of the Hungarian Scientific Academy and professor of chemical technology in the Technical University in Budapest, died at the age of sixty-five on December 28. He received his degree in chemical engineering in 1908 at the Technical University in Budapest, and then he was appointed assistant there. In 1920 he was appointed Privatedocent, and in 1923 professor in the Institute for Chemical Technology. He worked in the field of the hydrogenation of coal and coal-tars and made several valuable contributions to the scientific problems involved and industrial applications. Arguing with Bergius-who first liquefied coal-he proved by classical experiments that the hydrogenation of coal is 
a catalytic process. He found, first, that the molybdenum and tungsten sulphide catalysts are not poisoned by sulphur compounds. On the contrary, the presence of sulphur compounds is advantageous. This discovery has been embraced in many foreign patents (Britain, United States and France) and is referred to in the scientific literature as the 'Varga effect'.

Prof. Varga's main purpose in life was the development of the Hungarian chemical industry, on which he also worked as Minister of Industry during 1939-43. Students always enjoyed his lectures, which showed not only the real connexion between science and technology, but-through the industrial life of the country and by picturing the industrial development in the free world-also the right way to be followed in the dark days of oppression.

In 1932 he was elected a member of the Hungarian Scientific Academy, and he also received many other scientific distinctions.

His last studies concerned hydrogen transfer reactions, which have been applied for the mild pressure hydrogenation of highly asphaltic crudes with high sulphur content. After successful laboratory experiments, a pilot plant was built, the results of which he reported to the sixth World Power Conference at Vienna in 1956.

\section{NEWS and VIEWS}

\section{Prof. H. A. Brück: Astronomer Royal for Scot-} land

Prof. H. A. Brück, whose appointment as Astronomer Royal for Scotland and professor of astronomy in the University of Edinburgh in succession to the late Prof. W. M. H. Greaves has just been announced, was formerly a pupil of Sommerfeld in Munich. His career in astronomy began at the Astrophysical Observatory, Potsdam, where in 1930 he became a member of the assistant staff. There he worked on a number of problems concerning the solar spectrum, in co-operation with E. Finlay Freundlich, and also took an important part in the Potsdam survey of stellar spectra in the Kapteyn Areas of the southern sky. In 1936 political difficulties forced him to leave Germany. After a short stay at the Vatican Observatory, he went to Cambridge, first as a junior observer at the Solar Physics Observatory, later becoming assistant director of the Observatory and John Couch Adams Astronomer. During these years he undertook pioneer work on the photoelectric measurement of line profiles in the solar spectrum. $\mathrm{He}$ also collaborated with W. Moss in an early investigation of $H \alpha$ and $D_{3}$ lines in solar prominences, and afterwards with F. Ruttlant attempted the extremely difficult problem of detecting photographically a displaced calcium $K$ line from matter ejected by a chromospheric flare.

In 1947 the Irish Government decided to revive the Dunsink Observatory, which had been closed for many years, to form a part of the Dublin Institute for Advanced Studies, and Brück agreed to become the director. Under his guidance a new solar telescope and a large spectrograph were built, and work on photoelectric photometry of stars, including studies of star scintillation, was started. A co-operative agreement with the Armagh and Harvard Observatories was made, to allow Dunsink a share of the 24-36-in. Baker-Schmidt telescope at Bloemfontein, South Africa. Among many other activities Brück himself found time to go with D. A. Jackson to Khartoum for the 1952 total solar eclipse, where they measured chromospheric line widths interferometrically in difficult conditions. In 1955 the International Astronomical Union met in Dublin, and much of the success of these meetings was due to Brück's enthusiasm and tact as the local organizer. In this exacting task he was ably assisted by Mrs. Brück, who is herself an experienced solar physicist. Prof. Brück will take up his new appointment with the good wishes of an unusually wide circle of astronomical friends.

\section{Structural Engineering in the University of Man- chester: \\ Dr. W. Merchant}

Dr. Wilfred Merchant has been appointed to the recently established chair of structural engineering in the Faculty of Technology of the University of Manchester. Dr. Merchant graduated with first-class honours in engineering science at Oxford in 1933. $\mathrm{He}$ then spent four years in gaining industrial and municipal experience in the design and detail of steel and reinforced concrete frames and foundations. In 1937 he was elected to a Commonwealth Fellowship which he held at the Massachusetts Institute of Technology, specializing in soil mechanics. During the War, Dr. Merchant was engaged on the development of jet engines in the Gas Turbine Engineering Department at Metropolitan-Vickers, Ltd., Manchester, and joined the staff of the Manchester College of Science and Technology in 1946 as a lecturer in structural engineering. Since his appointment there, his research work has been mainly concerned with structures, though he remains a member of committees of the Aeronautical Research Council and the Gas Turbine Collaboration Committee. In 1951 he was promoted to a readership in applied mechanics and he proceeded to the degree of D.Sc. in 1955. Dr. Merchant has published a number of papers and reports on soil mechanics, on aerodynamics and on structures in various scientific journals and is joint author of a recently published volume entitled "An Introduction to the Theory of Structures".

\section{Nuclear Research and Development in Europe}

M. Louis Armand (France), Herr Franz Etzel (Germany) and Prof. Francisco Giordani (Italy) have been visiting the United Kingdom on behalf of the six governments now negotiating the Euratom Treaty-Belgium, France, the Federal Republic of Germany, Italy, Luxembourg and the Netherlandsto "report on the amount of atomic energy that can be produced in the six countries in the near future and on the means whereby this can be achieved". They have already visited the member-countries of the proposed Euratom Treaty, and recently visited the United States for talks with the United States Atomic Energy Commission. M. Armand is directorgeneral of the French State Railways and president of the Industrial Equipment Committee of the French Atomic Energy Commission; Herr Etzel is senior vice-president of the High Authority of the Coal and Steel Community; Prof. Giordani is president of the Italian National Research Council and 